\title{
Histopathological study of invasive and non-invasive Entamoeba spp. in experimental rats
}

\author{
Athraa Abd-ulameer Al-Hilfi', Maha Khalil Al-Malak and Muslim Abd-ulrahman Al-Tomah
}

\begin{abstract}
Background: The genus Entamoeba has many species that are invasive or non-invasive (E. histolytica, E. dispar, and E. moshkovskii).The invasive E. histolytica is the main pathogenic amoeba in human. Amoebiasis involves several stages starting with the adherence of the parasite to the intestinal epithelium, followed by degradation, tissue invasion, and distribution to other organs.

Results: The current study investigates the pathological changes of Entamoeba spp. infection in both rectum and cecum of experimental rats. The results showed the histological changes at the 7th, 14th, and 28th day post-infection for the three species. E. histolytica and E. moshkovskii infection showed less pathological changes compared to E. histolytica. These changes include the attachment of the trophozoites to the mucosal layer, significant surface epithelial changes such as dissociation and degeneration in the mucosal layer, and ulceration of the apical surface. Inflammatory cells infiltrate the varied regions, extending into the deep mucosa causing mild architectural alterations. These are features of amoebiasis.
\end{abstract}

Conclusion: The pathological changes reported in E. dispar and E. moshkovskii were less severe than E. histolytica.

Keywords: Amebic colitis, Pathogenesis, Degeneration, Mucosal layer, Entamoeba spp

\section{Introduction}

Amoebiasis is a gastrointestinal infection caused by a number of Entamoeba spp., and E. histolytica is the main species to cause the pathological symptoms of this disease. It is widely spread, causing mortality and morbidity across the world through diarrhea. E. histolytica has the ability to invade the intestinal mucosa and form abscess in parenchymal tissues such as the liver, lungs, and brain. Furthermore, other Entamoeba spp. may cause human infection including $E$. dispar and E. moshkovskii (Roure et al. 2019).

All the three species are morphologically alike and colonized in the human intestine. Recently $E$. dispar has been identified as a non-invasive species (Uslu et al. 2016); however, it has a big effect on the epidemiology of amoebiasis. Moreover, it has asymptomatic infection worldwide (Al-Areeqi et al. 2017). E. moshkovskii, like E. dispar, has a genetic relationship with $E$. histolytica. It

\footnotetext{
* Correspondence: athraarose90@yahoo.com

Department Biology, College of Science, Basra University, Basra, Iraq
}

spreads normally in different environments and might cause human infection (Khomkhum et al. 2019), and it was diagnosed in fecal samples of patients with gastrointestinal symptoms in Australia, Bangladesh, India, Iran, Tanzania, and Turkey, suggesting that $E$. moshkovskii act as a causative agent of amoebiasis (Shimokawa et al. 2012).

The pathogenesis of E. histolytica is caused by several virulence factors found in the trophozoite stage, which can invade the intestinal mucosa and spread through the bloodstream. It may also cause extraintestinal lesions, mainly in the liver. One of these virulence factors is the cysteine proteinase, which plays a crucial role in tissue invasion of E. histolytica (Rangel-Castañeda et al. 2019). Secondly, the amoebapores, small peptides which form pores in the cell membranes of the target cells and cause a big outflow of extracellular $\mathrm{Ca}^{+2}$, which is linked to the release of amoebic proteases at the contact location. Furthermore, the degeneration of substrates and inflammatory response can occur during E. histolytica infection, the parasite has the ability to resist immune response by 
the degradation of complement component (Saha et al. 2015). At the beginning of the parasite infection, a flaskshaped ulceration is formed as a result of several cysteine protease expressions, causing the degradation of the extracellular matrix (Shirley et al. 2018). Due to the related work of cysteine proteases and amoebapores, the cell will be detached and absorption in the surface of the intestine will be reduced. Generally, cysteine proteases have many targets including mucin, extracellular matrix (ECM) components, tight junction proteins, immunoglobulin's, complement, and cytokines. After destroying these components, the cell debris will be phagocytized by the amoeba (Cornick et al. 2016).

Amoebiasis has intestinal and extraintestinal manifestations. The invasive intestinal amoebiasis have four forms, and all of them are acute, including bloody diarrhea, colitis, amebic appendicitis, and ameboma of the colon. The invasive amoebiasis counts for $90 \%$ of the dysenteric symptoms (Debnath et al. 2019).

Colorectal amoebiasis can have different clinical manifestations, ranging from asymptomatic to severe necrotizing colitis. For this reason, an accurate diagnosis is needed, such as rectal biopsy which may reveal the presence of the parasite and eliminate the possibility of a carcinoma (Hardin et al. 2007). E. moshkovskii is recently recorded as a pathogenic species. The sources of this species varies from the sewage, river, lake freshwater, brackish water, and samples of human feces (Lopez et al. 2015). They may have different pathological changes in the intestine. The aim of the current study is to investigate and compare different histological changes in the intestine during the infection of E. histolytica, E. dispar, and E. moshkovskii using rats Rattus norvegicus as an animal model for amoebiasis.

\section{Materials and methods}

Forty male experimental rats Rattus norvegicus were used, aged 8-10 weeks and weighing 110-120 g. They are divided into four groups. Each group was introduced with the pathogenic species through injection, oral inoculation $\left(10^{4} \mathrm{cyst} / \mathrm{ml}\right)$ and intra rectal (100 trophozoites $/ \mathrm{ml}$ ). Animals were killed after 7, 14, and 28 days of infection. Parts of the large intestine (cecum and rectum) were taken for histological study. Histological preparation for light microscope was performed according to Drury et al. (Drury et al. 1967).

\section{Results}

\section{Histological study}

The histological changes in experimental rat cecum and rectum for the three Entamoeba. spp. are illustrated as follow:
Histological changes in E. histolytica experimental infection

Cecum Cecum sections from large intestines of control rats showed that the smooth surface of the mucosal layer has shallow plicae but no villi. This layer is composed of two types of cells that can be distinguished from each other, the absorptive cells and the mucous cells. In addition, simple tubular (crypts of Lieberkuhn) intestinal glands are also present. The submucosa consists of loose connective tissues with blood vessels. The tunica muscularis is composed of strands of (smooth) muscle fibers extending upward. These layers surrounding the lumen are filled with fecal materials (Fig. 1).

Histological analysis of cecum sections of rats infected with amoebiasis $-E$. histolytica at 7 days post-infection showed trophozoites attached to the surface of the epithelial layer, causing destruction of mucosa, degeneration of the interglandular epithelium, and hyperplasia in other crypts at variable regions of cecum. Furthermore, infiltration of inflammatory cells within the lamina propria was noticed (Plate 1).

The development of lesions at 14 days post-infection showed the destruction of the mucosa, cytolysis of the apical portion, and degradation of the epithelium lining of the crypts, as well as infiltration of inflammatory cells in the base of the crypts (Plate 2A). The results clarified the changes of infected cecum at 28 days post-infection with $E$. histolytica and revealed that dilation of interglandular epithelium can be seen, inflammation in variable regions, and formation of granulomas. Also, edema in the submucosal layer as well as thickening of the wall of muscularis externa can be seen (Plate 2B).

Rectum Rectum sections of the control rats showed the lining of mucosa by simple columnar epithelium. The

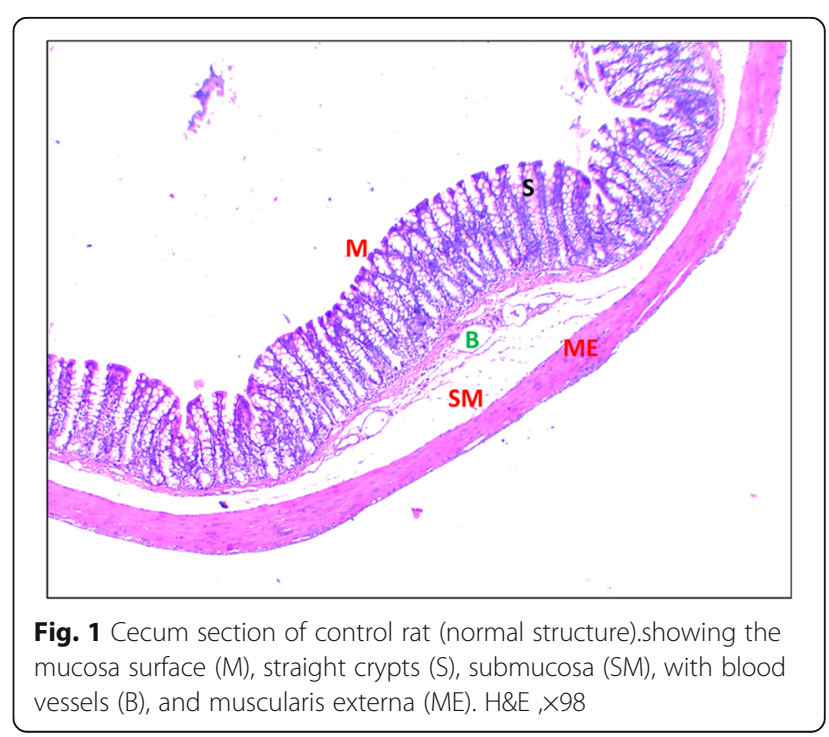




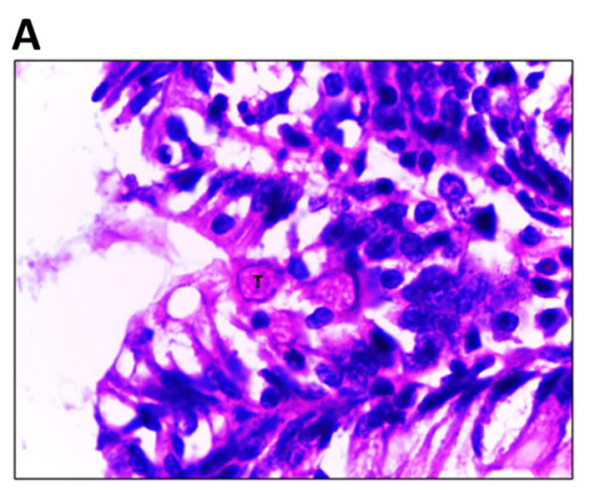

B

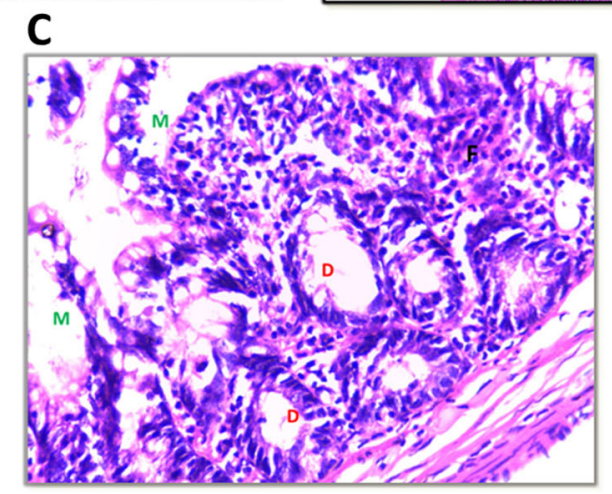

Plate 1 Histological changes in the cecum of rats infected with E. histolytica 7 days post-infection. A Showed the trophozoite (T) attached to the surface epithelial layer. H\&E stain, $\times 948$. B Showed destruction of epithelial layer (D) and hyperplasia of crypts (C). H\&E stain, $\times 40$. C Showed destruction of mucosa (M), degeneration of interglandular epithelium (D), heavy infiltration of inflammatory cells within lamina propria (F) H\&E stain, $\times 379$.

intestinal glands are longer and filled with goblet cells. These glands extend from the surface to the muscularis mucosa. The longitudinal folds contains a core of submucosa covered by the mucosa. The submucosa consists of loose connective tissues which are highly vascular. The muscularis externa has a smooth inner circular muscular layer and outer longitudinal muscular layer (Plate 3)

Microscopic photography showing the histological changes of infected rectum at 7, 14, and 28 days postinfection revealed the attachment of the trophozoites to
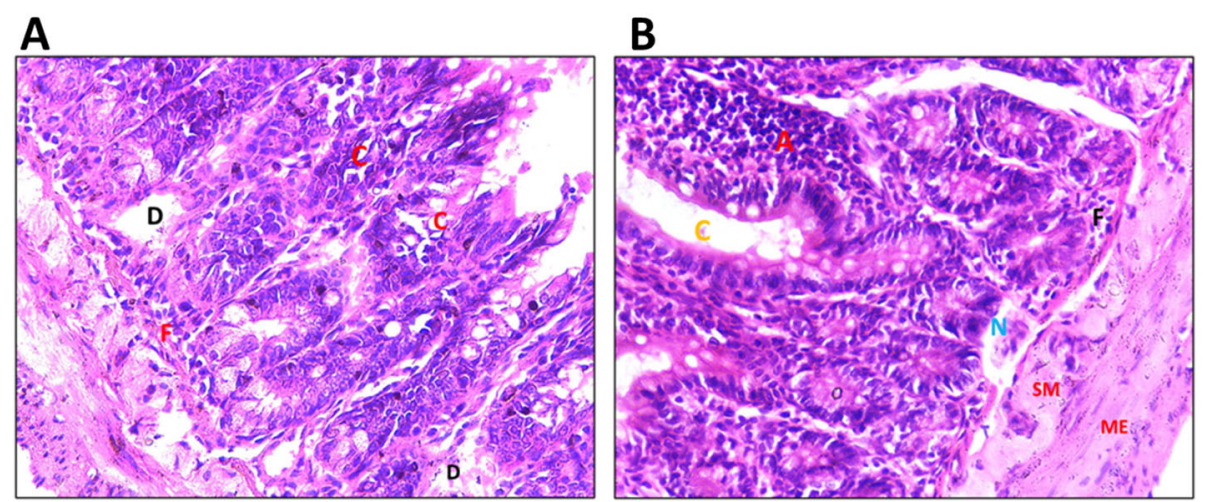

Plate 2 Histological changes in the cecum of rats infected with E. histolytica. A Transverse section of infected rat with E. histolytica 14 days postinfection. Showed cytolysis of the apical portion of crypts (C), degradation of the epithelium lining of the crypts (D), and infiltration of inflammatory cells (F). H\&E stain, X379. B Transverse section of infected rat with E. histolytica 28 days post-infection. Showed aggregation of inflammatory cells (A) as granuloma, inflammatory cells near the muscularis mucosa (F), dilated intestinal crypts (C), edematous submucosa (SM), necrotic material $(\mathrm{N})$, and thick muscularis externa wall (ME). H\&E stain, $\times 379$. 


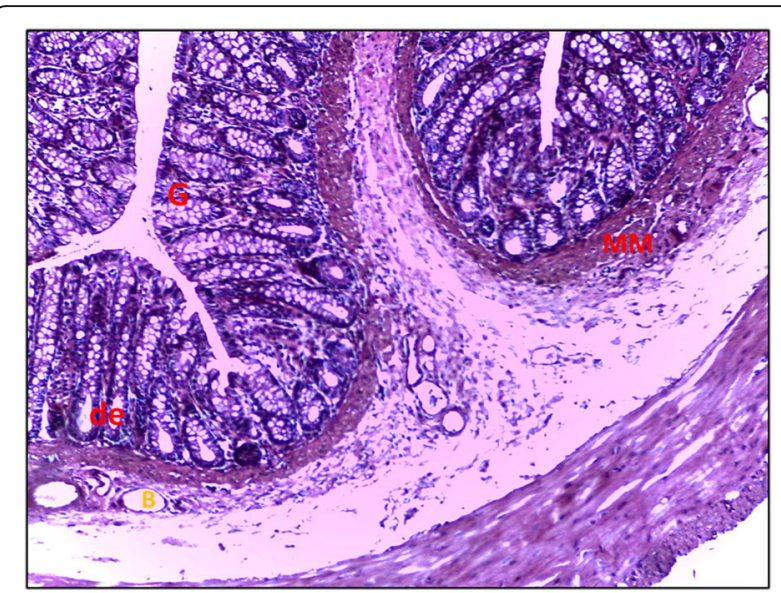

Plate 3 Transverse rectum section of control rat (normal structure). Showed the longitudinal, deep crypts(de), goblet cells (G), muscularis mucosa (MM), blood vessels in submucosa (B). H\&E stain $\times 379$

the mucosal layer. Furthermore, thick mucosa was lined by simple columnar epithelium, the presence of branch intestinal hyperplasia of crypts and heavy infiltration of inflammatory cells were obvious at 7 days post-infection (Plate 4).
At 14 days post-infection, the degeneration of the submucosa and crypts and the thickening wall of muscularis externa can be seen (Plate 5A). The findings of the infected rat's rectum at 28 days post-infection showed the mucosa with ulceration of the apical surface as well as lining of crypts along abundant goblet cells. Other changes including edematous submucosa can also be seen (Plate 5B).

\section{Histological changes in E. dispar experimental infection}

Cecum Histological changes found in sections of the cecum associated with $E$. dispar 7 days post-infection showed mild changes in the mucosal layer architecture represented by flat surfaces, in addition to elongated crypts that lined with high number of goblet cells. Moreover, infiltration of inflammatory cells distributed within the lamina propria can be seen (Plate 6A). Two weeks post-infection, this period also showed a lymph nodule with active germinal center as well as heavy infiltration of inflammatory cells (Plate 6B). Light microscopic observations on cecum sections from infected rats with $E$. dispar at 28 days post-infection revealed unclear mucosal layer and deep crypts with mild degeneration of some
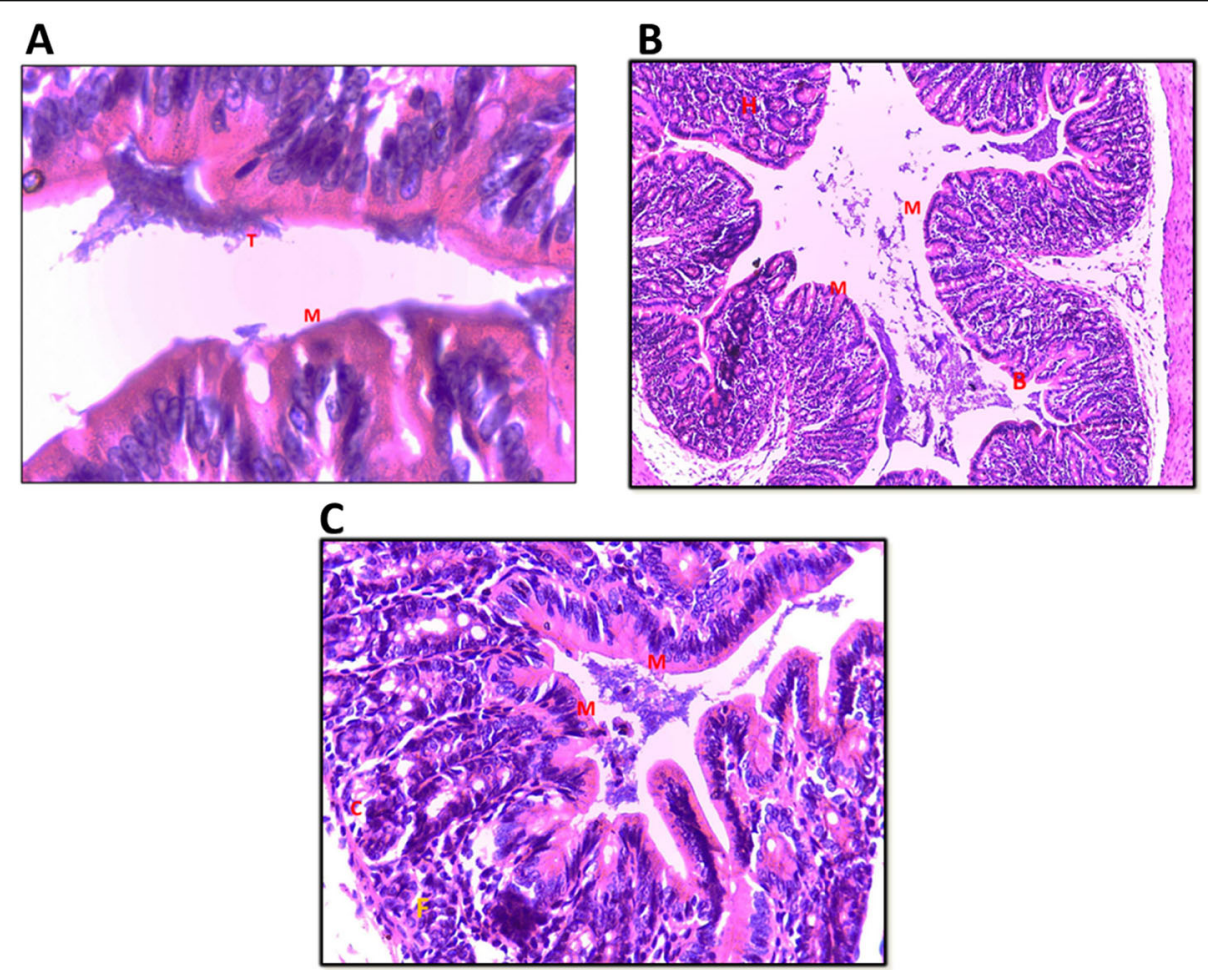

Plate 4 Histological changes in the rectum of rats infected with E. histolytica 7 days post-infection. A Showed the attachment of trophozoite (T) at the surface mucosa (M). H\&E stain, X948. B Showed the mucosa as folds (M), hyperplasia of crypts (H), and branched intestinal crypts (B). H\&E stain $\times 98$. C Showed thick mucosa lined by simple columnar epithelium (M), destruction of some crypts (C), infiltration of inflammatory cells (F). H\&E stain $\times 379$ 

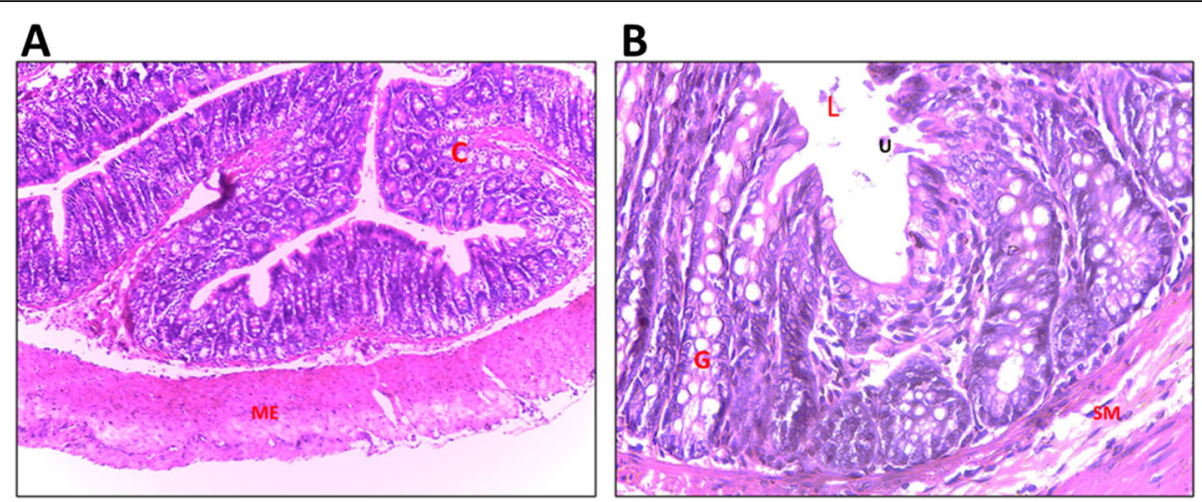

Plate 5 Histological changes in the rectum of rats infected with E. histolytica. A Rectum section of infected rat with E. histolytica 14 days postinfection. Showed the degradation in the submucosa (SM) and in the crypts (C), thickening wall of muscularis externa (ME). H\&E stain, $\times 98$. B Rectum section of infected rat with E. histolytica 28 days post-infection. Showed atrophied, contracted lumen $(L)$, mucosa with ulceration of the apical surface (U), goblet cell hyperplasia (G), edematous submucosa (SM). H\&E stain $\times 379$

crypt base. We can also see a regular muscular mucosa and submucosa (Plate 6C).

Rectum Changes in the rectum tissue of infected rats at 7 days post-infection with $E$. dispar revealed the degeneration in the lamina propria mucosa. Furthermore, there was infiltration with high number of inflammatory cells that appeared crowded (Plate 7A). At 14 days postinfection of $E$. dispar, there was degeneration in the mucosal layer in addition to infiltration of inflammatory cells in varied regions (Plate 7B). The findings in the rectum of infected rats at 28 days post-infection showed
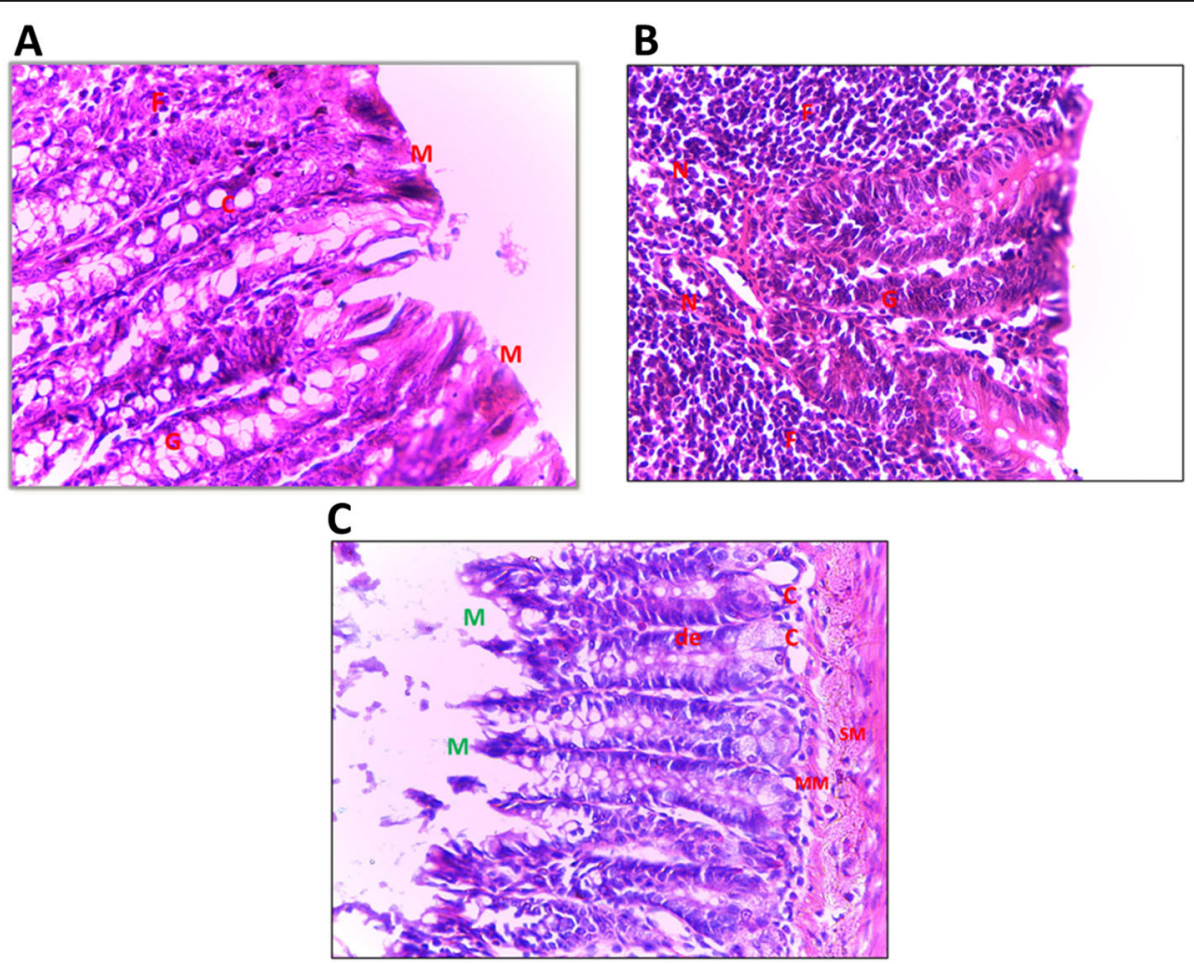

Plate 6 Histological changes in the cecum of rats infected with E. dispar. A Flat surface in cecum section of infected rat with E. dispar 7 days post-infection. Showed flat surface of mucosa (M), elongated crypts (C) lined with goblet cells (G), and infiltration of inflammatory cells (F). H\&E stain $\times 379$. B Transverse cecum section of infected rat with E. dispar 14 days post-infection. Showed the crypts (G) extend downward and penetrate the lymph nodule with active germinal center $(\mathrm{N})$, heavy infiltration of inflammatory cells (F). H\&E stain, $\times 379 . . C$ Transverse cecum section of infected rat with E. dispar 28 days post-infection. Showed unclear mucosal layer (M), deep crypts (de), mild degeneration of some crypt base (c), and regular muscular mucosa (MM) and submucosa (SM). H\&E stain $\times 379$ 


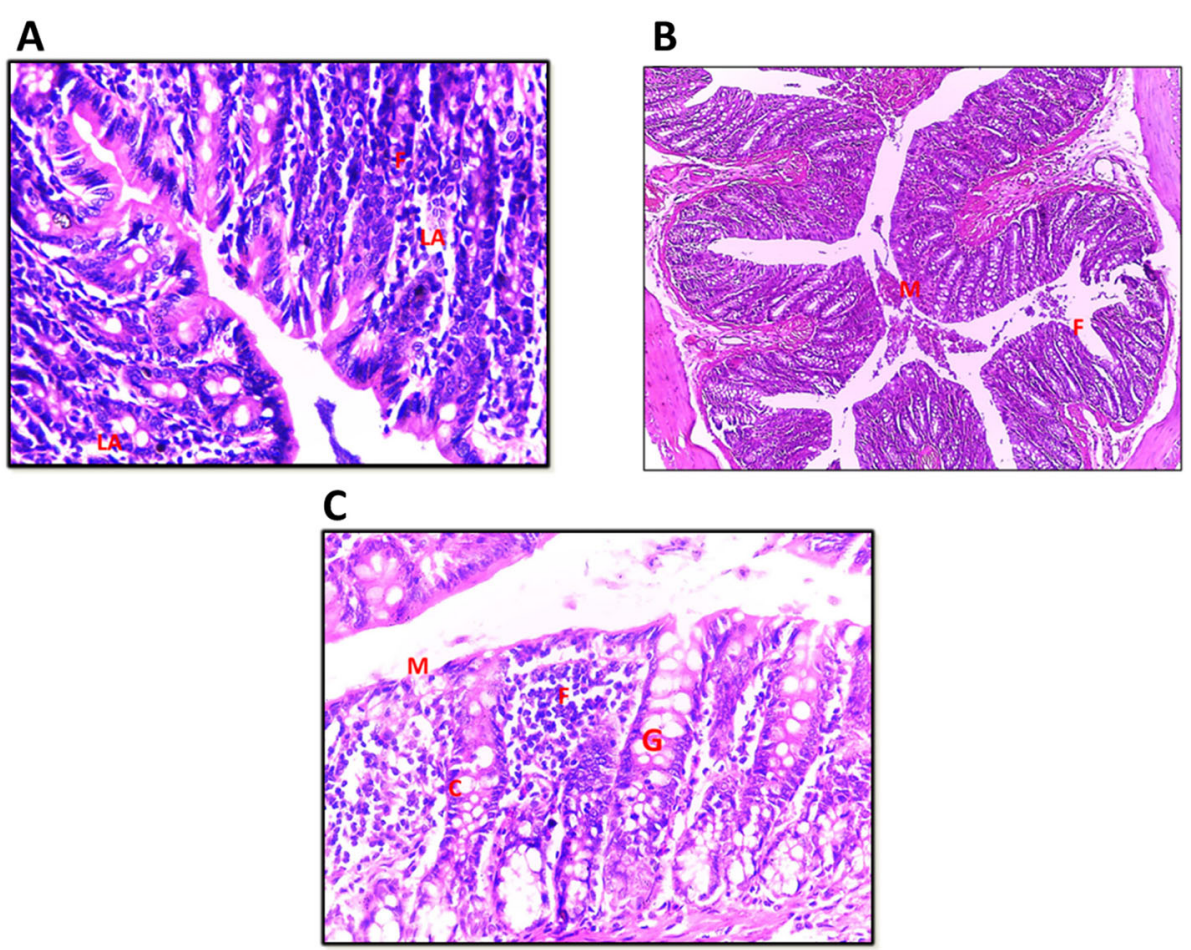

Plate 7 Histological changes in the rectum of rats infected with E. dispar. A Transverse rectum section of infected rat with E. dispar 7 days postinfection. Showed degeneration in the lamina propria (LA) and heavy infiltration of inflammatory cells (F). H\&E stain $\times 379$. B Transverse rectum section of infected rat with $E$. dispar 14 days post-infection. Showed degeneration in the mucosal layer (M) and mild infiltration of inflammatory cells (F). H\&E stain $\times 98$. C Transverse rectum section of infected rat with E. dispar 28 days post-infection. Showed degenerated mucosal layer (M), elongated crypts (C), goblet cell hyperplasia (G), and moderate inflammatory cells within lamina propria (F). H\&E stain ×379

degeneration in the mucosal layer and elongation of crypts lined with an increased number of goblet cells, in addition to inflammatory cells diffused within lamina propria around the crypts (Plate $7 \mathrm{C}$ ).

\section{Histological changes in E. moshkovskii experimental infection}

Cecum The histological observations in the cecum of infected rats with E. moshkovskii at 7 days postinfection showed dissociation and degeneration in the mucosal layer and heavy infiltration of inflammatory cells (Plate 8A). Figures on sections from cecum related to infected rats with E. moshkovskii at 14 days post-infection showed moderate alteration including disorganized mucosa and mild inflammatory cells (Plate 8B). Observation of light microscopy on cecum sections from infected rats with E. moshkovskii at 28 days post-infection showed the presence of lymphocytes aggregating and forming what is known as the gut-associated lymphoid tissue (GALT) within the submucosa. Also, heavy infiltration of inflammatory cells in the lamina propria with dilated blood vessels can be noticed (Plate 8C).
Rectum Findings from rectal histological sections of infected rats with E. moshkovskii at 7 days post-infection clarified heavy inflammatory cells on the mucosal layer, dilated blood vessel, and edema in the submucosa as well as, debris and amorphous material in the lumen (Plate 9A). Moderate changes in rectum structure were observed at 14 days post-infection with E. moshkovskii; the crypts were lined by a large number goblet cells, in addition to the presence of focal inflammation (Plate 9B). The results 28 days post-infection showed that the lymph nodule in the submucosa extended to lamina propria. Inflammatory cell aggregation can also be seen (Plate 9C).

\section{Discussion \\ Histological study}

As it is known, amoebiasis can be intestinal or extraintestinal. In cases of intestinal amoebiasis the symptoms ranged from asymptomatic cases to acute colitis and chronic colitis. Normally, less than $10 \%$ of patients have symptoms and most of this $10 \%$ exhibit symptoms similar to chronic colitis (Ichikawa et al. 2016).

Sections of the intestinal tract, particularly the cecum and rectum of the infected rats revealed the adhesion of the Entamoeba sp. trophozoites to the surface of the 

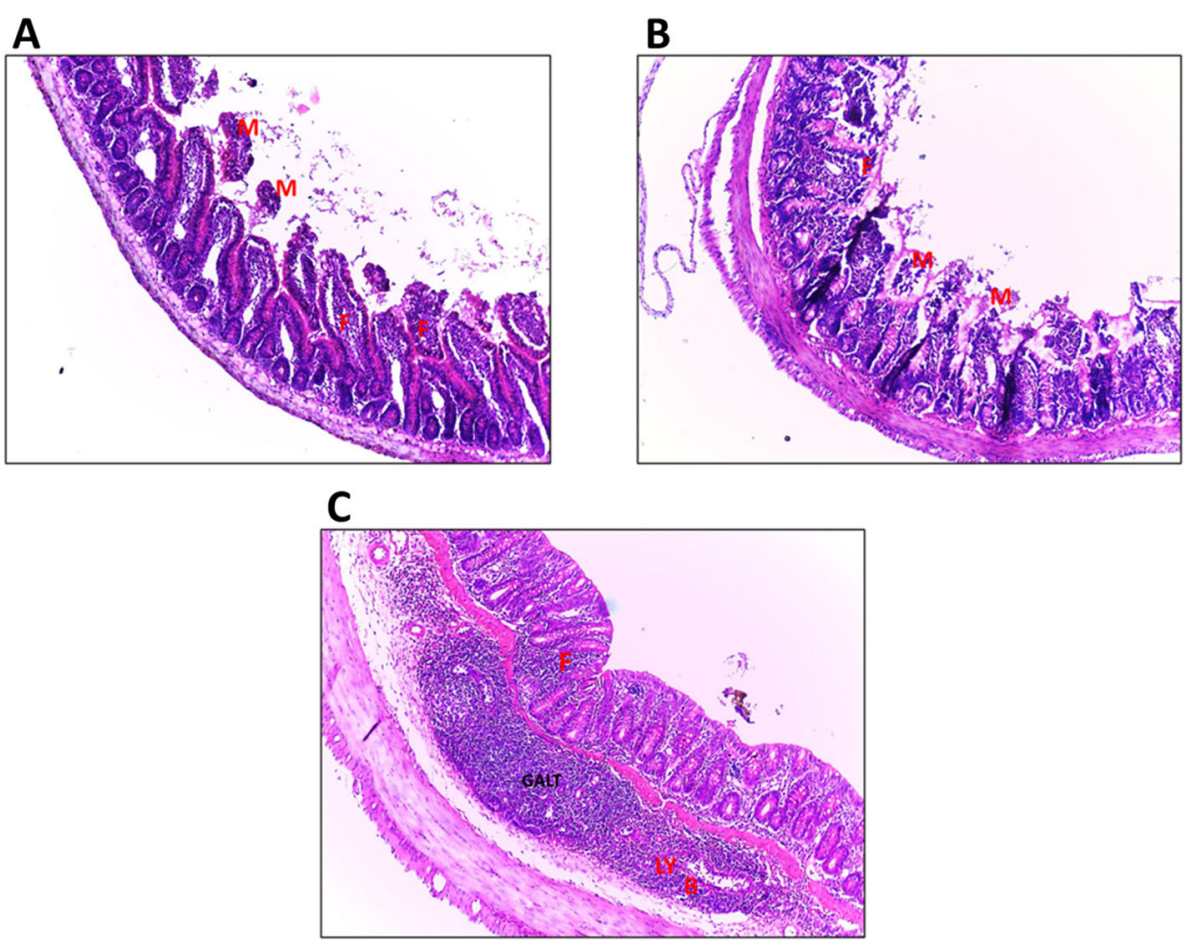

Plate 8 Histological changes in the cecum of rats infected with E. moshkovskii. A Transverse cecum section of infected rat with E. moshkovskii 7 days post-infection. Showed dissociation and degeneration in the mucosal layer(M) and heavy infiltration of inflammatory cells (F). H\&E stain $\times 98$. B Transverse cecum section of infected rat with E. moshkovskii 14 days post-infection. Showed mild inflammation (F) dissociation and degeneration in the mucosal layer (M). H\&E stain X98. C Transverse cecum section of infected rat with E. moshkovskii 28 days post-infection. Showed gut-associated lymphoid tissue (GALT) within submucosa, heavy infiltration of inflammatory cells in the lamina propria (F), dilated blood vessel (B), and lymphocytes (LY). H\&E stain $\times 98$

intestine. The mechanism of this attachment can be explained by the filopodia which are cytoplasmic projections of the trophozoite. These filopodia will attach to the substratum and cause cytolysis of the host cells (Lushbaugh and Pittman 1979). The trophozoites' adhesion stops the trophozoite from transforming in to a cyst as it is known that free trophozoites that migrate to the large intestine could transform in to a cyst via binary fission (Kantor et al. 2018).

Another pathological change caused by E. histolytica is the degeneration of the epithelial layer and a heavy infiltration of inflammatory cells in to these layers. The reason of this degeneration is the ability of trophozoites to attach and lyse the epithelial layer of the intestine through the Gal/GalNAc lectin. In addition, a certain enzyme might be involved in increasing the risk of a parasite's invasion, for example, sialidase which is $\mathrm{N}$ acetylgalactosamidase and it is essential for removing a polysaccharide from mucin cells (Cornick and Chadee 2017). This removal allows the trophozoite to lyse the protective mucous layer and gradually penetrate the epithelial layer of the colon. The penetration will increase the risk of parasitic metastasis to different organs in the host body. Furthermore, different mechanisms participate in the death of the epithelial layer cells. These mechanisms involves the parasitic virulence factor such as cysteine protease. The cysteine protease targets the cells causing the lysis of these cells via apoptosis. In addition to that, another virulence factor is involved, which is amoebapore, a serine-rich $E$. histolytica protein known to have such an effect (Quach et al. 2014).

As mentioned in our results, there was a formation of ulcer. The invasive species of Entamoeba such as E. histolytica causes colonic mucosal ulceration as trophozoites eat their way through the mucosa. In rare cases of long-stand infection, it causes masses that are ulcerative, inflammatory, big, and similar to carcinomas. Focusing on the pathological changes during Entamoeba spp. infections, the amebic colitis is represented by the thickness in the mucosa, in addition to inflamed and edematous mucosa (Hardin et al. 2007).

Hyperplasia found in our result can be explained by the degeneration of the epithelial layer. At the beginning of the infection, a non-specific lesion can be formed as a result of glandular hyperplasia and stromal edema (Espinosa-Cantellano and Martínez-Palomo 2000). Normally, the gastrointestinal mucosa has the ability to repair the damage but when the integrity of the mucosa is 

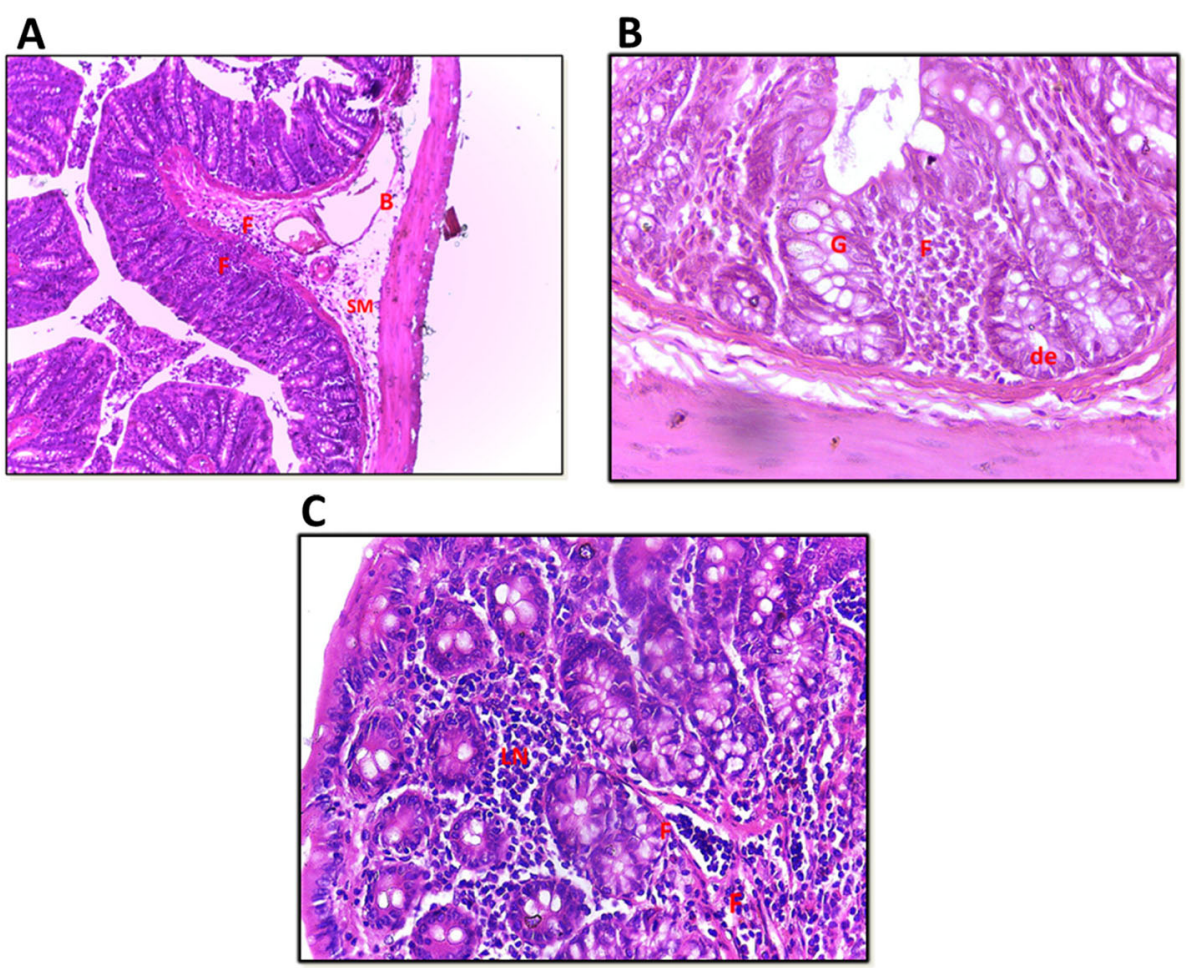

Plate 9 Histological changes in the rectum of rats infected with E. moshkovskii. A Transverse rectum section of infected rat with E. moshkovskii 7 days post-infection. Showed dilated blood vessel (B) of submucosa, edema in submucosa (SM), and heavy infiltration of inflammatory cells (F). H\&E stain $\times 379$. B Transverse rectum section of infected rat with E. moshkovskii 14 days post-infection. Showed focal inflammation (F), deep crypts (de), and goblet cell hyperplasia (G). H\&E stain $\times 379$. C Transverse rectum section of infected rat with E. moshkovskii 28 days post-infection. Showed lymph nodule in submucosa extending to lamina propria (LN) and aggregation inflammatory cells (F). H\&E stain ×379

damaged, the repairing process will rely on the epithelial cells' ability to migrate and proliferate. Moreover, the epithelialization can occur to replace the mucosal defect. It is important to maintain a balance between cell loss and cell renewal as excessive cell loss might lead to atrophy or ulceration. On the other hand, excessive proliferation of the cells and long life span might lead to hyperplasia (Jones et al. 1999).

The goblet cells in the intestine synthesize and secrete mucin as a result of stimulation by a number of stimuli. Our results showed hyperplasia in these goblet cells which might be explained as adaptation of these cells to mechanical stimulation or injuries caused by the parasite. During its colonization, trophozoites bind to mucin oligosaccharide and Gal/GalNAc lectin to penetrate the mucosal layer. During this process, the amoeba degrade the mucin barrier and eventually attach to the epithelial cells (Nakada-Tsukui and Nozaki 2016).

The infiltration of inflammatory cell which formed in the crypt of rats at 14 and 28 days post-infection is already confirmed by other researchers as a result of long-term infection (Ghosh et al. 2019). Parasite infection for a long time leads to intestinal layer invasion and inflammation in case of no treatment. Another pathological change that we saw in our study is edema which results from inflammation that led to fluid exudation. The exudation is caused by the high permeability of blood vessels resulting in the leakage of blood fluid at the site of infection (Zhen and Zhang 2019).

In the 28-day period, the symptoms were more severe. The presence of the parasite in the intestinal layers will increase the symptoms. The formation of granulomas may be the result of the aggregation of immune cells known as macrophages to prevent the parasite from spreading (Espinosa-Cantellano and Martínez-Palomo 2000). The results showed the presence of the parasite in the rectum, similar to Hardin et al.'s (Hardin et al. 2007), who studied the invasive species of amoeba and the formation of ameboma rectal mass. The reason why the rectum can be infected with Entamoeba spp. is that it is considered to be a temporary storage site of feces, in addition to the presence of fluid which allow the trophozoite to attach to the surface of the epithelium and invade the tissue (Ooi and Seow-Choen 2003).

Regarding $E$. dispar infection, our study showed less pathological changes compared to E. histolytica due to less virulence factors in former species. For example, $E$. histolytica secretes approximately 10 to 1000 times more 
cysteine proteases than E. dispar. Moreover, the amoebapore secretion is approximately $1 / 3$ of that secreted by the E. histolytica. Finally, E.dispar showed a reduced rate of adhesion and cytotoxicity than $E$. histolytica (Oliveira et al. 2015). Lack of granuloma in our results are similar to other researchers. For instance, Espinosa-Cantellano et al. (Espinosa-Cantellano et al. 2007) who infected hamsters with $E$. dispar via intra hepatic route found that it formed a focal inflammatory cell to infiltrate with no granuloma which might be the result from the incapability of $E$. dispar to establish experimental lesion because it is considered to be a commensal parasite. Another study (Dolabella et al. 2012) reported the establishment of amoebic liver abscess by $E$. dispar.

Regarding E. moshkovskii, which is originally classified as a free-living protozoan found in anoxic sediments and environments such as brackish coastal pools, are found to infect humans in some cases (Shimokawa et al. 2012). In animal model, special murine model E. moshkovskii caused diarrhea, weight loss. and colitis. In Bangladesh, cases showed the association between E. moshkovskii infection and diarrhea in children were similar to E. histolytica (Hamano et al. 2006).The experimental infection of $E$. moshkovskii was reported in the ceca of $\mathrm{C} 3 \mathrm{H} / \mathrm{Hen}$, $\mathrm{C} 3 \mathrm{H} / \mathrm{Haj}$, and $\mathrm{CBA} / \mathrm{J}$ mice, but not $\mathrm{C} 57 \mathrm{BL} / 6$ or $\mathrm{BALB} / \mathrm{c}$ mice, while $E$. dispar failed to infect any experimental mice. The ability of E. moshkovskii and E. histolytica to infect murine model is due to shared virulence factors which are not found in E. dispar. This joint feature of $E$. moshkovskii and E. histolytica leads to similar symptoms including diarrhea and blood stool (Mojarad et al. 2010).

\section{Conclusion}

E. dispar and E. moshkovskii were found to be pathogenic species in experimental rats and their presence were associated with diarrhea. These species showed varied histological changes in rats' intestine. However, the histological changes in E. histolytica were more severe. This study helped confirm and further understand the pathogenesis of both E. dispar and E. moshkovskii.

\section{Abbreviations}

ECM: Extracellular matrix; Gal/GalNAc lectin: Galactose/N-acetylgalactosamine lectin

\section{Acknowledgements}

The authors wish to especially thank Dr. Sanaa Jameel Thamer,of the Department of biology, College of Science, Basra University for her help in working at the center laboratory. Also, the authors would like to appreciate Dr. Mohammed Hussein Minati and Dr. Shereen Jawad Al-Ali, of the Department of biology, College of Science, Basra University, Basra, Iraq for their kind assistances and advices in writing the manuscript.

\section{Authors' contributions}

All work is done by AA except the diagnosis which was performed by MK and MA. AA was a major contributor in writing the manuscript. All authors read and approved the final manuscript.
Funding

The authors declare that they have no funding sport during this study.

Availability of data and materials

Not applicable

\section{Ethics approval}

All ethical guidelines have been adhered according to the committee on the ethics of dealing with laboratory animals.

\section{Consent for publication}

Not applicable

\section{Competing interests}

The authors declare that they have no competing interests.

Received: 26 September 2019 Accepted: 15 October 2019

Published online: 29 November 2019

\section{References}

Al-Areeqi MA, Sady H, Al-Mekhlafi HM, Anuar TS, Al-Adhroey AH, Atroosh WM, Dawaki S, Elyana FN, Nasr NA, Ithoi I, Lau YL, Surin J (2017) First molecular epidemiology of Entamoeba histolytica, E. dispar and E. moshkovskii infections in Yemen: different species-specific associated risk factors. Trop Med Int Health 22(4):493-504

Cornick S, Chadee K (2017) Entamoeba histolytica: host parasite interactions at the colonic epithelium. Tissue Barriers. 5(1):1283386

Cornick S, Moreau F, Chadee K (2016) Entamoeba histolytica cysteine proteinase 5 evokes mucin exocytosis from colonic goblet cells via av $\beta 3$ integrin. PLoS Pathogens. 12(4):1005579

Debnath A, Rodriguez MA, Ankri S (2019) Recent progresses in amebiasis. Front Cell Infect Microbiol 9(247):1-4

Dolabella SS, Serrano-Luna J, Navarro-García F, Cerritos R, Ximénez C, GalvánMoroyoqui JM, Silva FE, Tsutsmi V, Shibayama M (2012) Amoebic liver abscess production by Entamoeba dispar. Ann Hepatol 11(1):107-117

Drury RAB, Wallington EA, Cameron SR (1967) Carleton's histological technique, 4th edn, London

Espinosa-Cantellano M, González-Robles A, Chávez B, Castañón G, Argüello C, Lázaro-Haller A, Martínez-Palomo A (2007) Entamoeba dispar: infrastructure, surface properties and cytopathic effect. J Eukaryotic Microbiol 45(3):265-272

Espinosa-Cantellano M, Martínez-Palomo A (2000) Pathogenesis of intestinal amebiasis: from molecules to disease. Clin Microbiol Rev 13(2):318-331

Ghosh S, Padalia J, Moonah S (2019) Tissue destruction caused by Entamoeba histolytica Parasite: Cell Death, Inflammation, Invasion, and the Gut Microbiome. Curr Clin Microbiol Rep 6(1):51-57

Hamano S, Asgharpour A, Stroup SE, Wynn TA, Leiter EH, Houpt E (2006) Resistance of C57BL/6 mice to amoebiasis is mediated by nonhemopoietic cells but requires hemopoietic IL-10 production. J Immunol 177(2):1208-1213

Hardin RE, Ferzli GS, Zenilman ME, Gadangi PK, Bowne WB (2007) Invasive amebiasis and ameboma formation presenting as a rectal mass: an uncommon case of malignant masquerade at a western medical center. World J Gastroenterol 13(42):56595661

Ichikawa H, Imai J, Mizukami H, Uda S, Yamamoto S, Nomura E, Tajiri T, Watanabe N, Makuuchi H (2016) Amoebiasis presenting as acute appendicitis. Tokai J Exp Clin Med 41(4):227-229

Jones MK, Tomikawa M, Mohajer B, Tarnawski AS (1999) Gastrointestinal mucosal regeneration: role of growth factors. Front Biosci. 4(4):303-309

Kantor M, Abrantes A, Estevez A, Schiller A, Torrent J, Gascon J, Hernandez R, Ochner C (2018) Entamoeba Histolytica: updates in clinical manifestation, pathogenesis, and vaccine development. Can J Gastroenterol Hepatol 2018: $1-6$

Khomkhum N, Leetachewa S, Pawestri AR, Moonsom S (2019) Host-antibody inductivity of virulent Entamoeba histolytica and non-virulent Entamoeba moshkovskii in a mouse model. Parasit Vectors 12(1):101

Lopez MC, Leon CM, Fonseca J, Reyes P, Moncada L, Olivera MJ, Ramírez JD (2015) Molecular epidemiology of Entamoeba: First description of Entamoeba moshkovskii in a rural area from Central Colombia. PloS One. 10(10):0140302

Lushbaugh WB, Pittman FE (1979) Microscopic observations on the filopodia of Entamoeba histolytica. J Protozool 26(2):186-195 
Mojarad EN, Nochi Z, Sahebekhtiari N, Nejad MR, Dabiri H, Zali MR, Kazemi B, Haghighi A (2010) Discrimination of Entamoeba moshkovskii in patients with gastrointestinal disorders by single-round PCR. J Infect Dis. 63(2):136-138

Nakada-Tsukui K, Nozaki T (2016) Immune response of amebiasis and immune evasion by Entamoeba histolytica. Front Immunol 7(175):1-13

Oliveira FMS, Neumann E, Gomes MA, Caliari MV (2015) Entamoeba dispar: could it be pathogenic. Trop Parasitol 5(1):9-14

Ooi BS, Seow-Choen F (2003) Endoscopic view of rectal amebiasis mimicking a carcinoma. Tech Coloproctol 7(1):51-53

Quach J, St-Pierre J, Chadee K (2014) The future for vaccine development against Entamoeba histolytica. Hum Vaccin Immunother 10(6):1514-1521

Rangel-Castañeda IA, Carranza-Rosales P, Guzmán-Delgado NE, HernándezHernández JM, González-Pozos S, Pérez-Rangel A, Castillo-Romero A (2019) Curcumin attenuates the pathogenicity of Entamoeba histolytica by regulating the expression of virulence ractors in an ex-vivo model infection. Pathogens 8(3):127

Roure S, Valerio L, Soldevila L, Salvador F, Fernández-Rivas G, Sulleiro E, Manosa M, Sopena N, Mate JL, Clotet B (2019) Approach to amoebic colitis: epidemiological, clinical and diagnostic considerations in a non-endemic context (Barcelona, 2007-2017). PloS One. 14(2):0212791

Saha A, Gaurav AK, Bhattacharya S, Bhattacharya A (2015) Molecular basis of pathogenesis in amoebiasis. Curr Clin Microbiol Rep 2(4):143-154

Shimokawa C, Kabir M, Taniuchi M, Mondal D, Kobayashi S, Ali IM, Sobuz SU, Senba M, Houpt E, Haque R, Petri WA, Hamano S (2012) Entamoeba moshkovskii is associated with diarrhea in infants and causes diarrhea and colitis in mice. J Infect Dis 206(5):744-751

Shirley DAT, Farr L, Watanabe K, Moonah S (2018) A review of the global burden, new diagnostics, and current therapeutics for amebiasis. In: Open forum infectious diseases, vol 5. Oxford University Press, Oxford, US, p 7

Uslu H, Aktas O, Uyanik MH (2016) Comparison of various methods in the diagnosis of Entamoeba histolytica in stool and serum specimens. Eurasian Med 48(2):9-124

Zhen Y, Zhang H (2019) NLRP3 inflammasome and inflammatory bowel disease. Front Immunol 10(276):1-10

\section{Publisher's Note}

Springer Nature remains neutral with regard to jurisdictional claims in published maps and institutional affiliations.

\section{Submit your manuscript to a SpringerOpen ${ }^{\circ}$ journal and benefit from:}

- Convenient online submission

- Rigorous peer review

- Open access: articles freely available online

- High visibility within the field

- Retaining the copyright to your article

Submit your next manuscript at $\boldsymbol{\nabla}$ springeropen.com 